INTERNATIONAL JOURNAL OF RESEARCHES IN BIOSCIENCES, AGRICULTURE AND TECHNOLOGY (C) VISHWASHANTI MULTIPURPOSE SOCIETY (Global Peace Multipurpose Society) R. No. MH-659/13(N) www.vmsindia.org

\title{
BODY MASS INDEX OF ADOLESCENT GIRLS OF GOND MADIA COMMUNITY OF GADCHIROLI DISTRICT
}

\author{
Yogita K. Sanap ${ }^{1}$ and Kalpana Jadhav ${ }^{2}$ \\ ${ }^{1}$ Home science, Krishi Vigyan Kendra, Gadchiroli. \\ 2De partment of Home science, RTM Nagpur University, Nagpur.
}

\begin{abstract}
The term 'adolescence' re presents a hyper anabolic phase of growth, mediated by hormonal factors and characterised by peak velocities of growth. It is also a crucial phase of growth since it offers the second and last chance for the catch up with the growth in the life cycle of girls. Tribal population constitutes about $8 \%$ of the total population of India. They are at higher risk of unde $r$ nutrition because of their depe ndence on primitive agriculture practices and uncertainty of food supply. The Madia of Gadchiroli in Maharashtra district is found in the same localities as Gond proper and the re dialects are almost identical. Nutritional pattern in these years may be considered to be significant as it influences growth and reproductive maturation. The majority of girls selected in the study were 16 years old. The study was carried out in the area of Body mass index; significantly high percentage $(49.8 \%)$ of adolescent girls from the Gond-Madia community was underweight. The calorie intake of adolescent girls was $1301.6 \mathrm{Kcal} / \mathrm{d}$ significantly lower than the RDA for calories; however, after providing the nutrition related training, the girls indicated remarkable improvement by consuming more calories. Significantly high percentage of the people from Gond-Madia tribe is illiterate. After imparting nutrition education and supplementation there is remarkable change in their nutrient in take.
\end{abstract}

Ke ywords: Calories, BMI, Adole scent girls, Gond Madia.

\section{Introduction}

Adolescence a period of transition be tween childhood and adulthood is a significant period of human growth occurs with unique changes during this phase of life. The health of adolescence scattere d global attention in the past decade. In terms of the gender-related development index, India ranks 99 among the 130 countries included in the index (UNDP 1995). Gender inequality be gins even before birth and is consistently adverse throughout the life of the Indian women more than one way. Adolescent constitute over $21.4 \%$ of the population in India. This period needs special attention. Poor nutritional status during adolescence is an important determinant of health outcomes, especially for the females. The inadequate nutrition leads to underdevelopment such as short stature in adolescents. As health systems have accepted life-cycle approach, the proximity to biological maturity and adulthood may provide final opportunities to implement certain activities designed to prevent adult health proble ms. Hence the present study was undertaken to study the nutritional status of adolescents in rural area of Gadchiroli. (Deshmukh et al; 2006).

Tribal population constitutes about $8 \%$ of the total population of India. (Rao et al., 2006a). They are at higher risk of under nu trition because of their dependence on primitive agriculture practices and uncertainty of food supply (Rao et al., 2006b). In general, tribal communities in India are neglected, discriminated in te rms of income dis tribution and social status, which tend to have higher rates of undernutrition (Bisai and Mallick, 2011; Chakrabarty and Bharati, 2008). Recognizing these problems, the Government of India has been implementing several programs for overall development of the tribal communities (Rao etal., 2006). In spite of vulnerable segment of population, adolescent girl of many indigenous communities have suffered higher degree of undernutrition (Rao et al., 2006a; Bisai and Mallick, 201 1; Sil et al., 2011) and not received adequate attention. They are at higher risk of undernutrition because of their dependence on primitive agriculture practices and uncertainty of food supply (Rao et al., 2006b). In gene ral, tribal communities in India are neglected, discriminated in terms of income distribution and social status, which tend to have higher rates of undernutrition (Bisai and Mallick, 2011; Chakrabarty and Bharati, 2008). Assessment of nutritional status is considered as a measure of health and it is necessary for planners to understand the food and nutrition situation among tribal population for upliftment of these vulnerable groups.

\section{Materials and Method}

Gadchiroli is one of the districts of Maharashtra in India. The study was carried out in the year 2011 . The target population was 98 Gond madia adolescent girls of Gadchiroli, in the age group of 16 year. The selected adolescent girls were briefed on the objectives of the study and all of them gave consent to take part in the study. The anthropometric measurement 
included body weight. Weight was me asu re d with the subject standing and wearing light clothes to the nearest $0.1 \mathrm{~kg}$ using an electronic scale.Height is measured as standing height without boot or chapelwore by the subject.Boody Mass Index is calculated as Weight in Kilogram divided by height in meter. Precise information of food consumption pattern of the subjects was gathered through 24 hours recall method using an interview schedule. Intake of nutrient was computed using the values give $n$ in the nutritive value of Indian foods (Gopalan et al. 2001). The collected data were processed and statistically analyzed .'Z' test was used for analyzing the data.

\section{Results and Discussion Anthropometry Study}

Anthropometry is the hallmark technique of biological anthropology, and has become increasingly important in health assessments across this century. Although the need for accurate anthropometric measurement has been repeatedly stressed, the ways in which measurement error can influence the characteristics of anthropometric data is poorly appreciated. Besides, there are many communities living in remote geographical area that have not been studied in detail, and the Gond-Madia community of Gadchiroli Dis trict is one such community. However, in this study, the focus was on the adolescent girls (of age group 16 year) of this region. The results of the anthropometric assessments are presented he reunder.

\section{Height and Weight of the Adole scent Girls}

Height and weight are used to calculate body surface area (BSA) and body mass index (BMI). These measurements have implications for epidemiologic research, health and nutritional status assessments of a population and planning for interventions for various disorders. Height measurements alone are an important indicator of nutritional status, bone health, and various health problems. In view of the importance of these parameters data was collected from the adolescent girls belonging to Gond-Madia tribe of Gadchiroli and the results are presented in following table 1 .

Table 1 Shows result of standing height of adolescent girls of Gond-Madia community of Gadchiroli District. On the basis of the statistical analysis of the collected data, it was observed that mean standing height of adolescent girls belonging to 16 years was $141.3 \pm 7.9 \mathrm{~cm}$. Subsequent to this, the standing height value observed was compared with the standard value (as given by Indian Council of Medical Re search i.e. ICMR). Hence, it is concluded that the standing height of the adolescent girls be longing to Gond-Madia tribe is remarkably less than the desired standing height (which also indicates desirable growth).

Based on the study of Baiga children (primitive tribals of Dindori district in Madhya Pradesh), Qamra et al., (2012) reported that the height of the adolescent girls is significantly lower than the desired height. Furthermore, Bisai and Mallick (201 1) also re ported that anth ropometric and nutritional status of adolescents belonging to Kora-Mudi child ren in West Be ngal is critical and hence, appropriate measures should be taken by the respective authorities to improve childhood health and nutritional status. In addition to this, Kshatriya and Ghosh (2008) also reported that the widespread prevalence of undernutrition among the adolescents of Dhodia, Kinnaura and Bhil tribal communities highlight a need for an integrated approach towards improving their health as well as the nutritional status. These results emphasize that the situation of adolescents belonging to different tribes is grim and needs urgent attention so that they can live a better life.

Table 2 shows results of assessment of body weight of adolescent girls of Gond-Madia tribe of Gadchiroli District. It was obse rved that ave rage body weight of girls belonging to age group 16 was $33.0 \pm 7.0 \mathrm{Kg}$ (Fig. 2). Furthermore, the assessment of the average body weight of adolescent girls with that of their desired standard body weight indicated that girls belonging to16 age group were significantly unde rwe ight (with the deficit being 28.9 to $38.7 \%$ from the desired body weight). Thus, the data clearly shows inadequate calorie intake by these girls.

The growth and development of the human beings is often indicated by the anthropometric measures such as height and weight. As earlier reported by Bhasin et al., (1990), body weight and height are the two prominent anthropometric measurements that are commonly used to evaluate growth and nutritional status of an individual. In view of this, the results obtained in this study show that the important growth indicators like height and body weight of the adolescent girls belonging to the Gond-Madia tribe are not as per expectations .Our results are congruent to those reported earlier by Sarupriya and Mathew (1988), who measured the height and weight of tribal adolescent girls (of 16 years of age) of Gogunda village of Rajasthan. However, there appears to be difference in our results and that reported by Gopalan and Styanarayana (1989), which can be 
attributed to the fact that their samples (adolescent girls) were selected from the major cities of India namely Delhi, Bombay and Coimbatore. The adolescent girls from these citie s have better height and body weight than that recorded with the girls of Gond-Madia tribes. Similarly, the height and weight of adolescent girls (of 16 and 17 years of age), be longing to low and affluent income groups of Coimbatore were recorded by Subapriya and Premakumari (1993), which also incidentally are better than that observed with the adolescent girls of Gond-Madia tribes.

In case of girls, achievement of optimal growth during adolescence is of highest importance, especially in view of maintaining sound health in future life. Growth monitoring by anthropometric measurements during this period, is not only an important health indicator but also a predictor of various morbidities in the community. Hence, the results obtained in this study clearly indicate an urgent need for intervention by the Government as well as NonGovernment Organizations with respect to the nutrition of adolescent girls of Gond-Madia community of Gadchiroli.

\section{Body Mass Index (BMI)}

BMI is a useful tool and for most individuals is an accurate way to classify weight,

Table 1: Mean Standing Height $(\mathrm{cm})$ of Tribal Adolescent Girls belonging to Gond-Madia Tribe of Gadchiroli district

\begin{tabular}{|l|l|l|l|l|l|l|l|l|l|}
\hline Age Group & $\mathbf{N}$ & Mean & SD & $\begin{array}{l}\text { S.V } \\
\text { (ICMR) }\end{array}$ & \% Deficit & Min. & Max. & MD & 't' \\
\hline 16 & 98 & 141.3 & \pm 7.97 & 162 & 12.74 & 123 & 156 & 20.63 & 25.62 \\
\hline
\end{tabular}

SD-Standard Deviation; S.V.- Standard Value; Min-Minimum; Max.-Maximum; MD-Mean Difference, 't'- 't' Value.

Table 2: Mean Body Weight (kg) of the Adolescent Girls belonging to Gond-Madia Tribe of Gadchiroli district

\begin{tabular}{|l|l|l|l|l|l|l|ll|l|}
\hline Age Group & $\mathbf{N}$ & Mean & SD & S.V. & \% Deficit & Min. & Max. & MD & 't' \\
\hline 16 & 98 & 33.0 & \pm 7.0 & 53.0 & 37.7 & 20 & 50 & 20.0 & 28.06 \\
\hline
\end{tabular}

SD-Standard Deviation; S.v.- Standard Value; Min-Minimum; Max.-Maximum; MD-Mean Difference, 't'- ' $\mathrm{t}$ ' Value.

Table 3: Distribution of the adolescent girls with respect to their BMI

\begin{tabular}{|l|l|l|l|ll|l|l|l|l|l|l|}
\hline \multirow{2}{*}{ Age } & \multicolumn{9}{|l|}{ Percentile } & \multirow{2}{*}{ Total } \\
\cline { 2 - 11 } & $\mathbf{0 - 5}^{\text {th }}$ & $\mathbf{5}^{\text {th }}$ & $\mathbf{1 5}^{\text {th }}$ & $\mathbf{2 5}^{\text {th }}$ & $\mathbf{5 0}^{\text {th }}$ & $\mathbf{7 5}^{\text {th }}$ & $\mathbf{8 5}^{\text {th }}$ & $\mathbf{9 5}^{\text {th }}$ & $\mathbf{9 7}^{\text {th }}$ & 99th $^{\text {th }}$ & \\
\hline \multirow{2}{*}{16} & $\begin{array}{l}\mathbf{6 1} \\
(62.24)\end{array}$ & $\begin{array}{l}4 \\
(4.08)\end{array}$ & $\begin{array}{l}11 \\
(11.22)\end{array}$ & $\begin{array}{l}6 \\
(6.12)\end{array}$ & $\begin{array}{l}11 \\
(11.22)\end{array}$ & $\begin{array}{l}5 \\
(5.1)\end{array}$ & - & - & - & - & 98 \\
\hline
\end{tabular}

Values in parentheses indicate percentage 


\section{Conclusion:}

As the study conducted it is found that the tribal adolescent girls who were of 16 years age group is significantly less than the desired height as recommended by ICMR. Along with remarkably under weight. Hence, it is concluded that tribal adolescent girls need adequate diet.

\section{Reference:}

Bisai S, Bose K, Ghosh A (2008). Nutritional status of Lodha children in a village of Paschim Medinipur district, West Be ngal, Indian J Public Health. , 52 (4):203-6.

Bisai S, Mallick C (2011). Prevalence of undernutrition among Kora-Mudi children aged 2-13 years in Paschim Medinipur District, West Be ngal, India, World J Pediatr.7(1):31-6.

Chakrabarty S \& Bharati P (2008). Physical Growth and Nutritional Status of the Shabar Tribal Adolescents of Orissa, India: a Crosssectional Study, Malays J Nutr. ,14(1):101-12

Deshmukh PR, Garg BS, Bharambe MS (2008). Effectiveness of weekly supplementation of iron to control anaemia amongadolescent girls of Nashik, Maharashtra, India, J Health Popul Nutr. ,26(1):74-8.

Dhingra R. (2011). An Assessment of Health Status of Adolescent Gujjar Tribal Girls of Jammu District, Post Graduate Department of Home Science, Unive rsity of Jammu, Jammu 180
004, Jammu and Kashmir, India, Stud Tribes Tribals, 9(2), pp.133-138

Nutrition Foundation of India (1990). Scientific Reports. Cited from Babitha B 2003. Nutritional status of adolescent girls and impact of short term food supplementation with special re fe rence to vitamin A and hemoglobin. Journal of Community Guidance and Research, 20(2): 121 131.

Qamra S., Shrivastava P., Roy J., (2012). Growth profile of Baiga children--a primitive tribe of District Dindori of Madhya Pradesh, India, Coll Antropol, 36(3):929-36.

Rao K.M., Balakrishna N., Laxmaiah A., Venkaiah K., Brahmam G.N., (2006). Diet and nutritional status of adolescent tribal population in nine states of India, Asia Pac J Clin Nutr., 15(1):64-71.

Rao KM, Balakrishna N, Laxmaiah A, Venkaiah K, Brahmam GNV (2006a). Diet and nutritional status of adolescent tribal population in nine states of India. Asia Pac J Clin Nutr.;15:64-71.

Rao KM, Kumar R Hari, Venkaiah K, Brahmam GNV. (2006b) Nutritional status of Saharia -a primitive tribe of Rajasthan. J Hum Ecol.;1 9:1 17-23.

Rao S.P., Bharambe M.S., (1993). Dental caries and periodontal diseases among urban rural and tribal school children, Indian Pediatr, 30(6):75964. 